\title{
Visual Teaching and Simulation Experiments of High Voltage Technology in the Post-modern Curriculum View
}

\author{
Ying $\mathrm{Ma}^{1 *}$ Huida Duan ${ }^{2}$ \\ ${ }^{1,2}$ School of Electrical Engineering and Information Technology, Changchun Institute of Technology, Changchun, China \\ *Corresponding author. Email: xiaomayinghappy@126.com
}

\begin{abstract}
The high voltage technology course is rich in content and abstract content, many course knowledge points, involving high voltage levels and limited daily teaching equipment. Build a virtual simulation experiment teaching project for high voltage technology. By building a platform such as DC withstand voltage virtual simulation experiment, we explore the digital online intelligent teaching method under the view of post-modern curriculum. Strengthen students' understanding of theoretical knowledge through practical application and realize independent, inquiry and cooperative learning ability.
\end{abstract}

Keywords: Virtual simulation, Postmodern view of curriculum, Digitalization, Smart teaching.

\section{INTRODUCTION}

With the development of China's ultra-high voltage and extra-high voltage technology, extra-high voltage technology occupies a leading position in the world. The development of its technology is inseparable from the breakthrough in high voltage technology. High voltage technology mainly solves the problems of overvoltage and insulation. With the development of power transmission engineering, new requirements are put forward for the research and improvement of various high-voltage devices. Therefore, high voltage technology, as the main professional course of electrical engineering and its automation, plays an important role in cultivating high quality technical talents for electric power system [1].

High voltage technology course is different from other professional courses, its content has strong abstract theory and strong practicality, involving a wide range of subject areas and knowledge structure, strong cross-fertilization of disciplines, and closer to the practical application of engineering [2]. Therefore, the high voltage technology course urgently needs to introduce new teaching methods to solve these problems. The high voltage technology experimental equipment is huge, high voltage level, complex system, high risk, etc[3]. The physical high voltage laboratory is usually a demonstration experiment, students observe, teachers guide, lack of students on the whole experimental process. In the post-modern curriculum perspective, emphasizing the "student-centered", the deep integration of information technology and traditional teaching models, the use of virtual simulation experiments can be repeated, easy to large-scale comprehensive training and other advantages, is conducive to promoting the development of education information technology, in order to improve the overall quality of student ability. At present, many universities have established virtual simulation laboratories, but there are still not many experimental projects for high voltage technology courses with strong engineering applications, so it is necessary to further explore the virtual wisdom teaching strategy, which is of great significance to improve the quality of teaching in professional courses [5].

\section{PROBLEMS IN THE IMPLEMENTATION OF TEACHING}

\subsection{Teaching Model}

The content of the high voltage technology course is many and scattered, and each part of the chapter lacks logic. This leads to difficulties for students to understand the degree of theoretical knowledge, and the course teaching method is mostly using traditional PowerPoint lectures and formula derivation, which leads to students not being able to understand theoretical knowledge in an image and profound way.

In addition, the theoretical part involved in the high voltage technology course poses a challenge to the experimental part of the course due to its high voltage level 
and dangerous practical operation. In turn, the high voltage technology course is a very practical course. In view of the above reasons, it is urgent to find a new teaching mode to solve the practical problems that cannot be solved by traditional teaching [4].

\subsection{Student Learning Status}

High voltage technology course is offered in the sixth semester. The current situation of teaching in this teaching stage has the phenomenon of "teaching deficiency". Students face "transitional exams" and do not allocate enough energy, such as studying for graduate school or taking the national grid entrance exam. Students' motivation is low and attendance is low, which makes it difficult to carry out teaching smoothly. Therefore, it is necessary to change the teaching mode and education concept to solve the phenomenon of "deflated teaching"[5].

\section{VIRTUAL SIMULATION EXPERIMENT PLATFORM WISDOM TEACHING CHARACTERISTICS}

High voltage technology virtual simulation experiments can be repeatedly operated, easy to large-scale comprehensive training and other advantages. Combining the characteristics of disciplines, taking scientific problems as the guide, taking scientific research or innovation and entrepreneurship training projects for college students as the carrier, cultivating students' scientific research thinking and promoting crossfertilization among disciplines. Through 3D simulation to simulate the operation state and working principle of highvoltage laboratory equipment, as well as experimental phenomena, directly observe or experience the working process of charge movement and corona discharge. Taking DC electric field impact discharge experiment as an example, the overall idea of virtual simulation experiment design is shown in Fig.1.

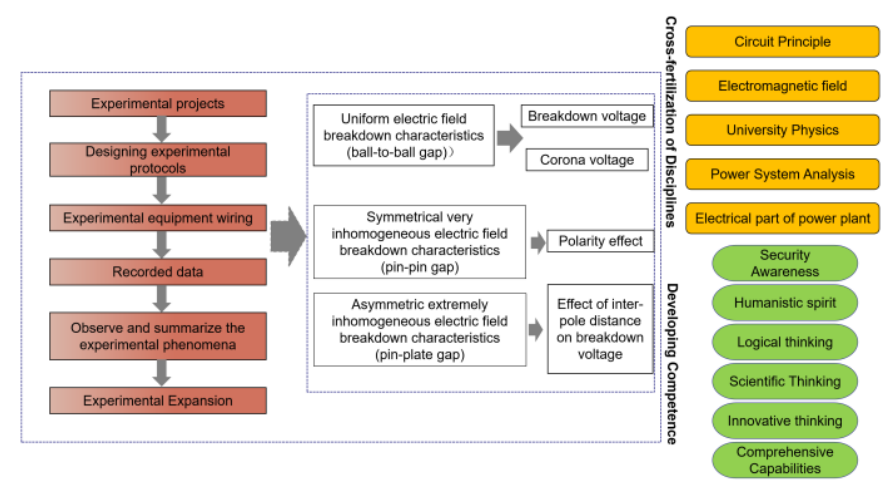

Figure 1 The overall idea of virtual simulation design experiment

\subsection{Recorded operation hours}

High voltage virtual simulation experimental platform for mastering the learning state and learning effect of students in the process of operation, in order to adapt to the traditional teaching in the form of change of the subject, set the operating hours of supervision. Including pre-study time, operation time, record time. The final system platform determines each score according to the operation process and the length of time.

\subsection{Continuous improvement of the experimental evaluation system}

The high voltage virtual simulation experiment platform can record the students' participation in the experiment process, and can conduct real-time experimental guidance. For students' pre-study effect, experimental steps, and experimental performance evaluation are equipped with perfect evaluation standards to ensure the fairness of the evaluation. The virtual simulation experiment platform establishes a perfect feedback mechanism, which gives suggestions, evaluation and feedback information to the participating students in various aspects, and conducts a comprehensive and systematic statistical analysis. The instructor improves the teaching effect by continuously and continuously improving and perfecting the experimental program.

\subsection{Expanding theoretical knowledge}

The virtual simulation project of high voltage technology is based on the existing electrical experiments, supported by virtual simulation and virtual reality technology, and built with the core of cultivating students' engineering practice ability. Take the DC electric field air gap discharge experiment in the virtual simulation project as an example. Through different electrode types to demonstrate the mechanism of high-voltage DC gap discharge under uniform electric field, extremely uneven electric field, and finally automatically form the electronic experiment report. With design, research and innovation links, it is a comprehensive experimental practice teaching program. It achieves the combination and complementarity of online and offline. It is a supplement, extension and expansion of the traditional experimental teaching mode. Moreover, through the opening of the network, the social education function of the experimental platform is explored, and the social value of the "virtual" experimental platform is given full play.

\section{HIGH VOLTAGE TECHNOLOGY VIRTUAL SIMULATION EXPERIMENT IMPLEMENTATION}

High voltage technology virtual simulation experimental teaching project in the implementation process, based on course knowledge points to design the corresponding virtual 
simulation experimental content. Set the corresponding teaching plan and teaching method during the implementation of the project. Set up in each virtual simulation experiment with multiple wisdom assessment scheme. Address geography and time control in order to stimulate students' learning interest and cultivate their practical ability [6].

\subsection{Virtual simulation experimental teaching course structure}

According to the high voltage technology syllabus, the teaching content is mainly divided into three major parts: dielectric electrical strength, electrical equipment insulation test, power system overvoltage and insulation. The structure of the experimental course designed according to the course content is shown in Fig. 2.

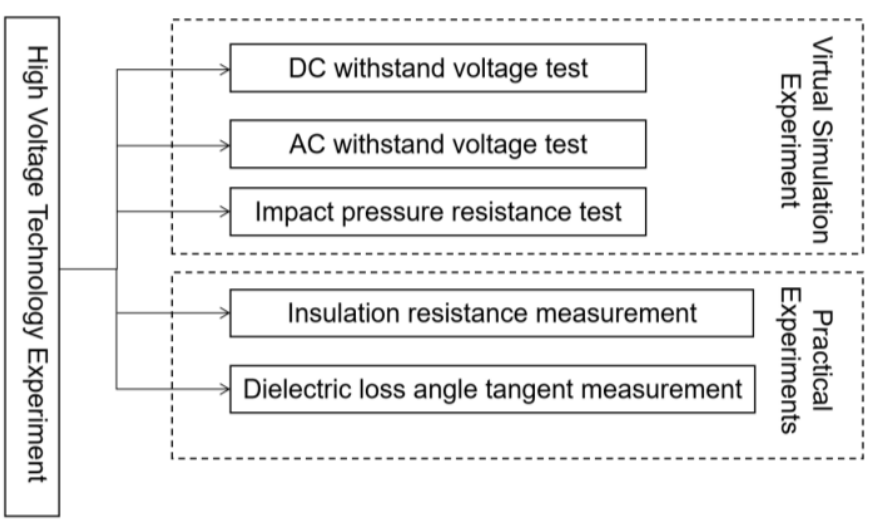

Figure 2 Experimental course structure

DC electric field in the air gap discharge virtual experimental equipment as shown in Fig.3. Virtual simulation of the experimental scene is highly restored, integrating design innovation, intelligent guidance, virtual experiments in one. The use of virtual reality technology to enable students to participate in the entire experimental process, to achieve the purpose of experiments to promote teaching, experiments to promote learning, in line with the principle of being able to real not virtual.

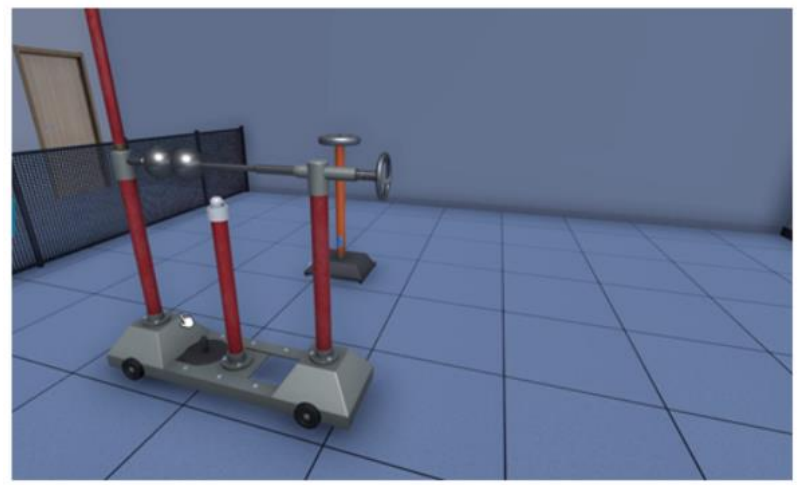

Figure 3 Ball gap discharge experiment in DC electric field

\subsection{Virtual simulation experiment content}

\subsubsection{Effect of electric field uniformity on breakdown voltage}

The virtual simulation experiment of high voltage discharge of air gap in DC electric field, in order to simulate air as an insulating medium, its breakdown characteristics are affected by the electric field form, the experimental content studies the air gap of plate to plate gap simulating uniform electric field, the air gap for plate gap simulating extremely uneven electric field, the air gap for plate simulating slightly uneven electric field in three electric field forms, through the determination of the three electric field forms, the breakdown characteristics under the action of different voltages The breakdown characteristics of the air gap are measured under different voltages in the three electric field forms to determine the breakdown voltage and the safety distance of the electrical equipment in the actual project.

\subsubsection{Analysis of the mechanism of polarity effect in a very inhomogeneous electric field}

The effect of electrode polarity on breakdown voltage is studied in a very inhomogeneous electric field composed of a needle and a plate. Through offline theoretical teaching lectures and virtual simulation projects as teaching aids, the whole discharge process of polarity effect can be understood intuitively and effectively.

\subsubsection{Development process of discharge along the surface}

All high-voltage electrical equipment should be designed to avoid discharge along the insulation surface during its operation. Through virtual simulation experimental projects, the entire discharge process is observed and solutions are found for improving discharge along the surface.

Through this virtual simulation experiment system, students can achieve the purpose of consolidating basic knowledge, exercising hands-on ability, verifying and further deepening the learning of high voltage discharge mechanism. In turn, students will be able to understand the course knowledge in layers and reach the degree of preliminary application.

\subsection{Virtual simulation experiment teaching method innovation}

\subsubsection{Transformation of a single mode of communication.}

The post-modern view of curriculum emphasizes studentcenteredness, changes the authority of the teacher, and 
pluralism and openness as a mainstream curriculum idea. And traditional teaching methods highlight the teacher-centered model of guiding students. Traditional high-voltage experiments have high voltage levels, high risk and other characteristics. High voltage experiments limit the scope of hands-on practice for students. Virtual simulation experimental teaching uses information technology and the depth of integration of traditional teaching methods to break such situation restrictions. Before the start of the experimental project, the platform sets the experimental pre-training session. The experimental pre-reading session includes five specific contents: experimental purpose, experimental principle, experimental wiring, experimental content, and precautions. Students are set to review the task, master the corresponding theoretical knowledge, and complete the corresponding experimental projects according to the experimental principles and experimental wiring. By changing the traditional single propagation mode and making full use of multiple propagation modes, geographic and time constraints are addressed. This approach can improve the subjectivity, experience and inquiry of students' learning.

\subsubsection{Motivational feedback teaching method.}

In the context of "deflated teaching", how to change the educational model and concept, so that students can allocate time more rationally, make full use of time, and motivate students to learn. In order to solve this problem, in the virtual simulation experimental project to carry out incentive scoring method. The experimental score mainly includes three modules: experimental equipment placement, experimental wiring, and link data. Each module score accounts for different percentages. Each completed item gets a corresponding score, that is, each operation step corresponds to a feedback link.

\subsubsection{Transformation of instruction.}

Instructors give appropriate guidance to the whole process before, during and after the whole experiment. This approach can stimulate students' sense of innovation, cultivate students' ability to identify problems, solve them and motivate them to learn, so as to better achieve the goal of talent training.

\subsubsection{Active values education.}

The background of post-modern curriculum view requires all-round training of students. The goal of teaching is to cultivate students with both knowledge and skills as senior talents. Behind the phenomenon of "deflated teaching" is the manifestation of students' utilitarianism, the manifestation of the pattern and vision of future learning development. The entrance exams and national network admissions exams serve as the threshold for students to enter the road of research and job hunting. Students focus purely on transitional exams and abandon their professional courses. Therefore, it is necessary to integrate values education into the classroom. That is, intersperse values education in the course of classroom instruction. Teaching students how to deal with exams and interviews, and even learning how to face failure in exams, correctly and reasonably guided, will help students' future development and growth, and will help improve the cohesiveness of the classroom.

\section{CONCLUSIONS}

In view of the high voltage technology course teaching content is much, abstract lack of logic. And the teaching involves high voltage level, not easy to operate and dangerous. The traditional teaching methods are challenged. Deep integration of information technology and traditional teaching. According to the teaching content design experimental projects, the use of virtual reality technology to highly restore the experimental scene, so that students participate in the entire experimental process to achieve a student-led teaching method for pointing. Promote universities to actively explore the new mode of personalized, intelligent and ubiquitous experimental teaching that combines online and offline teaching. Cultivating students to become superior talents with both knowledge and skills in various majors.

\section{ACKNOWLEDGMENTS}

Fund project: Ministry of Education University-Industry Cooperation Collaborative Education Project "Gas Media Pressure Test" (SF1081612296774);

Jilin Provincial Education Science "13th Five-Year Plan" Key (General Planning) Topics "Research and Practice of Smart Classroom for Power System Relay Protection Course"(GH19178);

"Teaching Reform and Practice of Electric Power System Analysis Course" of Industry-University Cooperation Collaborative Education Project of Jilin Provincial Education Department.

\section{REFERENCES}

[1] Tu Jiliang, Tao Qiuxiang, Liu Hui. Design and development of a comprehensive avionics and control virtual simulation experimental teaching system [J]. Experimental Technology and Management, 2019, 36(8). (In Chinese)

[2] Lu Yanli, Dong Wenqiang, Wang Yongxin. Construction and practice of virtual simulation experimental teaching center for materials majors [J]. Laboratory Research and Exploration, 2018, 37(11).153-157. (In Chinese)

[3] Zhou Chengxu, Wang Dongxia, Yudong Cao. Virtual simulation of digital signal processing Design of a comprehensive experimental platform $[\mathrm{J}]$. Journal of 
Liaoning University of Technology (Natural Science Edition), 2021, 41(1): 5-10. (In Chinese)

[4] Zhao Junfang, Cui Ying, Zheng Xinyao. Practical Problems of Flipped Classroom in Chinese Universities and countermeasures [J]. Modern University Education, 2018(6): 89-93. (In Chinese)

[5] Shan Juan, Liu Yan. Some Thoughts on Improving the Teaching Effectiveness of Probability Theory and Mathematical Statistics Course [J]. Research on Curriculum Education, 2019, 33: 174. (In Chinese)

[6] Guo Ting, Yang Shuguo, Jiang Yongheng, et al. Research on the construction and application of virtual simulation experimental teaching project [J]. Experimental Technology and Management, 2019, 36(10): 215-217,220. (In Chinese) 